Laparotomy has also been successfully done for pelvic abscess, for splenic abscess, for acute and chronic peritonitis, for hydatids of the peritonæum, for extraüterine fotation. Supra-vaginal hysterectomy in pregnancy with contracted pelvis (Porro's operation) has been often successful as a substitute for Cæsarean section; hysterectomy for the cure of uterine tumors I have already alluded to. 'That the abdomen could be opened, and an aneurism of an abdominal artery could be successfully treated, would not have entered into the wildest dreams of the most enthuiastic surgeon a score of years ago, and yet this has been accomplished lately by Professor Loreta, of Bologna. He opened the abdomen and found an aneurisin of the superior mesenteric artery; he tried to tie the artery above the aneurismal sac, but found this impossible on account of the adhesions of the sac to the neighboring viscera; by puncturing the sac with a small needle and introducing two yards of fine copper wire he succeeded - in producing coagulation and curing the aneurism.

My own operations now number two hundred and seventy laparotomies, of which two hundred are ovariotomies for the removal of cystic ovaries; several are cases of removal of ovaries and tubes for the cure of threatened or actual insanity; a very remarkable case of removal of a fibroid tumor of the abdominal parietes and peritonæum, and other laparotomies in which the abdomen was opened for various reasons.

I may be pardoned for uarrating at length another very remarkable instance of the curative influence of an abdominal incision. It is a case of tubercular peritonitis. A single girl, twenty-one years old, feeble, pale and emaciated, with a large belly full of fluid, came to St. Margaret's Home a year ago. It was supposed that she had an ovarian cyst. After she was etherized I saw that the fluid was probably ascitic; but I made an antiseptic (spray) exploratory incision to find out the cause of the dropsy. Much ascitic fluid ran out, and many flakes, masses, and layers of lymph. Tubercular deposits were seen scattered over the peritonæum and bowels. In short, the disease was tubercular peritonitis, as was shown from the gross appearances, and from the microscopic ${ }^{2}$ examination of masses of the peritonæum which I cut away. In about two weeks the wound opened spontaneously to allow the ascitic fluid, which had accumulated, to run out. The girl went home at the end of three weeks, and returned to the care of Dr. Tower, of South Weymouth. At the end of four months she had gained considerable flesh, and had a good appetite; occasionally she walked out when the weather was pleasant. All this time the opening in the scar of the abdominal incision had been discharging serum. In February of this year, the catamenia, which had been absent more than a year, reappeared, and have returned regularly since. I learned from Dr. Tower that the wound is now healed, and the general health has improved wonderfully, that she is fat and of good color, and is contemplating matrimony. 'This is, so far as I know, a unique case, and its treatment and cure are direct outgrowths from ovariotomy.

I have given but a brief sketch of what ovariotomy has led up to, of the successes and triumphs which the establishment of the harmlessness of opening the peritonæum has achieved, and I have shown that all these successful operations within the abdominal cavity owe their inception and execution to the knowledge gained by the ovariotomist and furnished by him to the profession.

"We should count time by heart throbs, not by figures on a dial." We should weigh the results and influences of our work, and not simply count and enumerate our operations.

I care but little for a man's statistics unless I know the character of his work. One may cure all his cases, another may have a mortality of twenty per cent. The former may have an exceptionally favorable series of cases. "You cannot juclge which has really done the most good, simply by the reported statistics.

But these remarks are foreign to the subject of my address. I only mean to say that on this day, the anniversary of our Society, it would be well for us to weigh our deeds and see what we have accomplished in our lives, and I am sure we should find that we have made immense advances in the treatment of morbid states of the organs within the abdominal cavity; and I think you will all agree with me that to the establishment of ovariotomy we owe all our progress in this direction.

\section{THE STUDY OF ANATOMY:}

ITS POSITION IN MEDICAL EDUCATION IN FNGLAND AND IN AMERICA.

BY G. H. MONKS, M.D.

AN American visiting the English medical schools must be struck with the amount of attention everywhere given to the study of anatomy, not only as an abstract science, but also in its more practical relations to clinical work. It may be interesting to examine the system followed there.

The regular lectures on descriptive anatomy are delivered, as elsewhere, by the professors, and present nothing peculiar. The recitations are, however, so far as I know, conducted almost exclusively by the demonstrators. Quain is the textbook preferred.

Little or no dissecting work is done without the help of some good manual of dissections. Ellis's guide is considered the most reliable and exhaustive; but those of Heath and Holden are also good and are considerably used. The demonstrators spend many hours of each day in the dissecting rooms, demonstrating and examining the students on fresh dissections. Material is so searce that all sorts of means are used to preserve it; and six or seven or even more students work upon the same body. The student has access to numbers of carefully made anatomical preparations, which have been so selected as to embrace nearly all the important parts of the body.

These are arranged with the special purpose of allowing the student to examine them and study from them to the best advantage. In most cases each structure is carefully labeled with printed tags. Some preparations, however, have no labels whatever, and are intended for purposes of exami- 
nation, and the student can at any time test his knowledge. Skeletons and bones, upon some of which the muscular attachments have been carefully traced, are also exposed to view.

"Quizzes" form an important feature in anatomical instruction. All parts of anatomy are passed over in review several times with the book, with fresh dissections or preparations.

The necessity for using all these means for learning anatomy will appear more evident when we see what is expected of the student at the central examining board, before which he usually appears at the end of his second year. This examination consists of a written and of a viva voce part. As for the written part no particulars need be given, except to mention that one or more of the questions calls for the description of some dissection. It is worthy of note that the information necessary to answer such questions cannot be gained by " cramming." The student must see in his own mind the exact relation of the parts, so as to be able to decide intelligently what skin-cuts he will make, what structures divide, and what draw aside. The following may be given as examples of this test question: Give the dissection necessary to expose the profunda femoris artery, or the posterior surface of the kidney, or the posterior interosseous nerve, or the great sciatic nerve external to the pelvis, or the parts concerned in inguinal or femoral hernia.

In the practical part of the examination the student must identify bones, assign them to the proper side, state bony connections, and mark in red chalk the muscular attachments. $\mathrm{He}$ is called upon to identify parts on alcoholic preparations, or on fresh dissections of special regions, and to answer whatever questions may be asked of him in connection with the same. As examples of alcoholic preparations may be mentioned sections of the brain, the diaphragm from above, the liver from below, the fundus of the bladder, the back of the wristjoint with tendons, and the ligaments of the kneejoint; and fresh dissections of such regions as the triangles of the neck, the pelvis, the muscles of the forearm, the buttocks (the glutens maximus being reflected), the popliteal space or the sole of the foot.

In most cases structures must be recognized by their relations, the neighboring parts of the body being, when possibly, concealed from view. The questions most frequently put are: What is this? If a muscle, what are its attachments and actions? If an artery, where does it arise and what are its branches? If a nerve, what parts does it supply? If a space, what are its boundaries and contents? And so on.

Such is the character of the anatomical study during the first two years, and of the examination which follows it. 'Thus far anatomy has been presented to the student as an abstract science, pure and simple. He is required from this point on to carry the more practical part of it along with him and incorporate it with his clinical work. He is taught to look at the human body as a whole, and to picture to himself the anatomy of the region which may underly any part of the integuments. In this way his anatomy previously learned with labor and painstaking is clinched and made of real practical use. The fact that anatomy is even harder to retain than it is to learn is recognized by the instructors. They realize that anatomical facts are isolated and have little connection with each other, and that these facts will be soon forgotten unless brought up again and again during elinical work. The student is therefore taught how to identify on the living body the bony processes, the tendons, and masses of muscle; to mark out the course of all the principal arteries, reins, and cutaneous nerves; to indicate the exact lines for incision in all the usual surgical operations, and to enumerate the parts cut through, the parts to be avoided, the number of arteries he may expect to tie, and so on. So well is he taught that he is expected to be able to tell with a fair degree of accuracy what structures a knife would wound if plunged into the body at any point, in any direction, and penetrating to any distance. At the bedside his anatomical knowledge is continually put to the test, until at last, by dint of much exercise and drilling, he does not fail to view any case in the light of its anatomical bearing, if any there be.

Questions like the following are continually put to him: This patient's femur has been broken transversely just above the knee. Why is a doubleinclined plane used instead of a weight and pulley? This man has hæmorrhoids. He has also a certain disease of the liver. How might trouble in the liver account for the piles? Here is a boy with an enlarged bursa in the popliteal space. Now, what are the bursæ in this region, and do you think this one communicates with the joint? This man here fell from a height upon his head. When he was picked up he was senseless and blood was flowing from one ear. A copious discharge of clear watery fluid followed. Now, why should these discharges indicate fracture of the base of the skull? What course does the pus of a vertebral abscess take to point in the groin? in the buttock? Here is a patient on whom colotomy was performed. Was the peritonæum opened? If not, what anatomical arrangement allows the operation to be done without touching the peritonæum? This boy has a congenital hydrocele. What is the difference between this and the ordinary hydrocele of the adult? Why may a patient with hip-disease complain more of pain in the knee than in the hip?

The examination which follows is conducted on the same general principles as the course of instruction just indicated. On the surgical examination paper one question at least is always devoted to surgical anatomy.

All these examinations are conducted by a central examining board whose members are chosen from the different medical schools. No student can be examined by instructors from his own school; thus favoritism is done away with, and each student is taken on his own merits only. Each school, therefore, simply prepares its students for the examination at the central examining board. The instructors at each school are thus stimulated to take a most active interest in getting as many men as possible through the examination, so as to maintain a good average. Owing to the small average number of students in each school the individual student receives a deal of personal attention from the instructors. 
'The habit acquired in student-life of associating anatomical facts with clinical work appears to be persisted in by the English practising physicians and surgeons, and they most certainly profit by it. It is almost impossible to compare our American methods of teaching anatomy with those commonly used in England, owing to the great variations in standard in the different American schools. Perhaps the most satisfactory comparison can be made if we take as a standard here the average of the best American schools. And if we make such a comparison it will, I think, appear evident to what extent our methods differ from the English ones in certain appreciable details, especially in regard to examinations, "quizzes," dissecting, and other practical work. We see, for instance, that there is in our system only one examination, as a rule, which may be written or oral, seldom both, and never very practical. This examination usually comes at the end of the first year, occasionally of the second. The questions are not generally so selected as to draw out the real practical knowledge of the student. A minimum of fifty per cent. is required to pass. It would be quite possible for most students to get this fifty per cent. by a fair knowledge of the textbook alone. I know of one student in one of our best schools who got a mark of ninety-eight per cent. without ever having seen the inside of the dissecting-room. Dissecting itself is not often made a prominent feature. If the student is required to dissect only three parts, few students are willing, and fewer still have the opportunity of dissecting more. In some schools it is only necessary to " take ont a dissecting-ticket." It occasionally happens that a student has no opportunity to dissect until the anatomical examination is over, in which case the stimulus to do good work is apt to be wanting. Besides this there is no requirement, and often no encouragement, to dissect with the aid of some good manual. Gray's Anatomy is certainly considerably overrated as a textbook, and as a dissector is much worse. One might overlook the fact that the student has not sufficient opportunities for learning anatomy from dissecting for himself, if preparations of good dissections were within easy reach. But the museums which contain such are usually closed to him, except on one or two days of each week when he has the opportunity of looking about for an hour or two. Under such conditions the sight of preparations is apt rather to excite his curiosity and admiration rather than to stimulate and assist him in his work.

Systematic "quizzes," by which the student's knowledge can be continually tested and so conducted as to fit him for his examination, appear to be the exception. By the middle of the first year the student finds that he can learn more rapidly, for the examination at least, by reading his textbook at home than by listening to lectures and demonstrations. Perhaps a certain amount of this "cramming" would be justifiable and even desirable, if the student could be examined at short intervals, before preparations or fresh dissections. Such an arrangement would be certainly of more benefit than reading through the text with nothing to make it clear but plates and diagrams. Besides this, the student has the advantage of being obliged to do the work of explanation himself. In schools where there is only one examination in anatomy the subject is completely dropped when once the examination is over; and there is hardly a single school in which the student is obliged to put his anatomical knowledge into working shape in connection with clinical work. Thus it must be evident how much lower is the standard of our system of anatomical instruction than that of the English schools. Should it be considered desirable to raise this standard the first step ought to be made by raising the standard of examinations. In a certain sense the standard of any given department can only be measured by the standard of the requirements, and not by that of the instruction. Especially does the standard of anatomy appear to be low in what might be called its practical aspects. In connection with the early anatomical examination a practical element might be introduced and the students examined, so far as possible, on fresh dissections and preparations. To assist the student in preparing for such an examination, special "quizzes," which may be called " small preparatory examinations," might be given, the museums might be opened, or at least a series of good anatomical preparations be exposed to view. If the demonstrators have no time for preparing such a set of specimens, they might be made by some of the most skilful pupils, paid, if necessary, for their work.

Many of the finest preparations at the Museum of the Royal College of Surgeons in England have been made by a non-professional man, specially hired for the purpose. Later on in connection with clinical examinations each student might be brought in turn before the living body and asked questions about the bony processes, tendons, arteries and anastomoses veins and branches, lines for incision in the usual surgical operations, the parts cut through, etc., the limits of internal organs, and lines for cutaneous nerves. He might be called upon to state what anatomical parts can be seen or felt and what surgical information gained by examination, digital or otherwise, of the different natural openings of the body, mouth, rectum, vagina, etc. Suitable instruction could easily be given for this examination, for it would only be necessary that clinical instructors should lay due stress upon the anatomical bearing of their cases, and that some practical instruction on external or applied anatomy should be given. If, in addition to this, the student is obliged to mark out all the lines for incision in the regular surgical operations, he will be in much better condition to profit by his operative courses on the cadaver later on.

There appears no valid reason why the English student should be better prepared in anatomy than the Amelican, but such is without the slightest doubt the case. It may be said that only a small amount of the practical anatomical knowledge possessed by American surgeons has been acquired from the regular course at a medical school. How much time would have been saved had it been otherwise.

It is but right, in conclusion, to call to mind the advances which have of late years been made in the anatomical department of Harvard University. Not only is the elementary instruetion in anatomy more thorough in the lecture and dissecting room, 
but in many other ways the students are offered greater facilities for learning. Certain practical courses on regional anatomy, medical and surgical, together with an examination in topographical anatomy at the end of the second year, are new departures, introduced with the evident desire of bringing the subject of anatomy into the position of prominence it deserves.

\section{$\longrightarrow$ \\ RECENT PROGRESS IN OTOLOGY.}

BY J. ORNE GREEN, M.D.

OTORRHEAS IN PHTHISIS.

THE character of otorrhœas in phthisical patients has for a long time been recognized as peculiar, both in their beginnings and in their course. The beginning of the disease is painless, the first symptoms noticed being a rapid loss of hearing, soon followed by one or more perforations of the drummembrane, unaccompanied by any marked inflammatory appearances on that membrane; these perforations rapidly enlarge, the membrane seeming to melt away without signs of ulceration, till of ten the whole membrana tympani is lost; this process is accompanied by but a slight amount of suppuration. Often the highest degrees of deafness are met in these cases, showing an involvement of the nervous structures as well as the tympanum. Healing in such cases is very exceptional, although it occasionally does occur from local treatment alone, and in other cases from local treatment combined with a residence in an appropriate climate.

The absence of pain, the rapid destruction, the involvement of the labyrinth, and the character of the secretion have led to the suspicion that the disease is a specific tuberculous process, and Nathan ${ }^{1}$ has recently investigated a considerable number of cases to determine the presence of the tuberclebacillus in the discharge. He examined forty cases of otorrhœa of all kinds, and in twelve of these found the bacilli in variable quantities. In eight of these twelve cases examination of the lungs and of the sputa proved the existence of tuberculous disease; in one such an examination was impossible; in the remaining three there were no symptoms outside of the ear pointing to tuberculosis, but caries was found in the ears. In the other twenty-eight cases of chronic and acute suppurations no bacilli were found.

Although these observations of Nathan's seem to show that the presence of the tubercle-bacillus is of value in a diagnostic point of view, Gottstein 2 asserts that such is not the fact; that in undoubted tuberculous otorrhœas the specific bacillus is sometimes present and sometimes not present; that its absence by no means justifies the exclusion of a tuberculous origin to the otorrhoea; and that a tuberculous otitis media purulenta resembles the tuberculous diseases of the bones and glands in which it has been proved that the bacilli are present in but a small number of the cases. These observations are based upon his own studies and a review of the literature of the subject.

1 Ueber das Vorkommen von Tuberkelbacillen bei Otorrhœn. Deutsches Archiv für klinische Medicin, xxxv.

Archive of Otology, xili.
EXTENSION OF A TYMPANIC ADHESIVE INFLAMMATION TO THE LABYRINTH.

An affection of the labyrinth as an accompaniment of the very common sclerosis (adhesive inflammation of Politser) of the tympanic mucous membrane has been so often recognized clinically that the labyrinthine disease is described as part of of the pathlogical process in most textbooks, although it has not yet been determined whether it is secondary to, or whether it occurs simultaneously with, the tympanic disease. Comparatively few observations, however, have demonstrated anatomically the labyrinthine lesion, and in this connection a recent observation of Moos and Steinbrügge ${ }^{3}$ is of interest.

The patient, it may be said, died from a hæmorrhage from the carotid artery produced by caries of the petrous bone resulting from acute purulent inflammation of one tympanum. The petrous bone on the other side was also examined, and showed chronic catarrhal changes in the tympanum in the form of adhesions between the crura of the stapes and the niche of the oval and round windows, and also a sclerosis of the mastoid cells, probably referable to a typhoid fever in the previous year. The interesting point was that the labyrinth also showed many changes : there was periostitis of the vestibule, with small hæmorrhagic spots and connectivetissue new growths; the membrane of the fenestra rotunda was thickened, and showed a deposit of friable cellular detritus on its inner surface, and a similar mass closed the aquæductus cochleæ; there was thickening of the utriculæ and the ampullæ, and much brownish-red and yellow pigment in the ampullæ, semicircular canals, and epithelium of the utricle.

\section{Ifeparti of Societieg.}

\section{THE AMERICAN OPHTHALMOLOGICAL SOCIETY.}

The Twenty-first Annual Session of this Society was held at the Pequot House, New London, Connecticut, July 15 and 16, 1885. The President, Dr. Willia F F. Norris, of Philadelphia, in the chair.

The first paper was entitled

OPERATION FOR REMOVAL OF DISLOCATED CRYSTALLINE LENS,

by Dr. C. R. AgNew, of New York.

The patient had been blind as long as he could recollect. The iris was tremulous, the lens was opaque and very movable. This eye had been painful for some time and recently the other eye had also attracted attention. The vision in this eye was $\frac{20}{15}$.

The operation for the removal was as follows: The pupil was dilated with atropia. The patient was then etherized and cocaine was applied. The eye was secured with fixation forceps. An instrument resembling a two-pronged fork, which was termed a bident was introduced into the vitreous chamber behind the dislocated lens, pressing it s Archive of Otology, xilt. 